\title{
ОСОБЕННОСТИ ФОРМИРОВАНИЯ МЕЖСЕКТОРНЫХ ВЗАИМОСВЯЗЕЙ В СЕАЬСКОЙ ЭКОНОМИКЕ
}

\begin{abstract}
Аннотауия. Основные источники развития сельских территорий традиционно рассматривают в контексте внешней поддержки со стороны государства, направленной на развитие АПК как основного сектора сельской экономики. В то же время на второй план отходят возможности межсекторного сотрудничества, основанного на местных ресурсах, - человеческих, культурных. Џель исследования: на основе изучения особенностей основных секторов сельской экономики оценить перспективы и возможности межсекторного сотрудничества, основанного на партнерстве представителей различных групп интересов (власти, бизнеса и населения) в целях повышении эффективности в управлении развитием сельских территорий. Объектом исследования являются сельские муниципальные образования Краснодарского края и, в частности, Крымский район как пилотный мунищипалитет, на базе которого проводились полевые исследования. Методом исследования является секторальный анализ. Научным результатом исследования стали расширенные трактовки сектора не только как части экономики (первичной, вторичный, третичный секторы), но и как части определенной системы властных отношений, социальной системы, системы пространственной организащии, отличающихся по своим специфическим характеристикам. Уточнено понятие «межсекторное сотрудничество»: оно трактуется как взаимодействие названных выше секторов в целях достижения солласованных целей на основе учета различий в интересах представителей различных секторов. Выделены факторы, способствующие налаживанию межсекторного сотрудничества и затрудняющие его развитие: ресурсы, компетенции, стили, и организация управления, предыдущий опыт. Прикладным результатом стали предложенные модели управления сельским развитием на основе межсекторного сотрудничества в отличие от существующих на практике, ориентированных на изменения в одном секторе.
\end{abstract}

Ключевые слова: сектор, межсекторные взаимосвязи, межсекторное сотрудничество, стратегическое планирование.

AVDEEVA TATYANA TIMOFEEVNA

Dr.Econ.Sci., professor of department of the organization and planning of local development FGBOOU WAUGH Kuban State University, e-mail:avdeevamanag@mail.ru

\section{THE TYPICAL FEATURES OF FORMING INTERSECTORIAL INTERCONNECTIONS IN RURAL ECONOMY}

\begin{abstract}
The main sources of development of rural territories are traditionally discussed in the context of external support from the government directed towards the development of the AIC as the main sector of rural economy. At the same time it is customary to sideline the capabilities of intersectorial cooperation based on local human and cultural resources. The goal of the study: based on studying the typical features of the main sectors of rural economy to evaluate the prospects and capabilities of intersectorial cooperation founded on a partnership of representatives of different groups of interest (government, business and population) in order to improve the effectiveness of management of development of rural territories. The scientific result of the study were expanded interpretations of a sector being not only a part of the economy (primary, secondary, tertiary sectors), but also a part of a certain system of governmental relations, a social system, a system of spatial organization distinguished by specific certain characteristics. We have clarified the definition of "intersectorial cooperation": it is interpreted as an
\end{abstract}


interaction of the aforementioned sectors in order to achieve the agreed upon goals based on considerations of differences in interests of representatives of different sectors. We have distinguished factors that encourage building intersectorial cooperation and impeding its development: the resources, competencies, styles and organization of management, previous experience. The applied result was represented by the suggested models of management of rural development based on intersectorial cooperation by contrast with the existing in practice oriented towards changes in one sector.

Keywords: a sector, intersectorial interconnections, intersectorial cooperation, strategic planning

Опыт стратегического планирования в сельских муниципальных образованиях Краснодарского края выявил целый ряд проблем и ограничений в развитии сельских территорий. Диагностика социально-экономической ситуации в ряде сельских районов показала, что в большинстве случаев при определении стратегических перспектив развития используется два подхода:

- подход на основе оценки конкурентных позиций территории вовне по группе заданных критериев (показателей) и в отраслевом разрезе. Он дает возможность проводить сравнение позиций муниципального образования на основе универсальных показателей;

- проблемный подход ориентирует на выявление проблем, связанных с достижением ключевых целей развития, - занятость, доходы, благоустройство населения, в конечном итоге - на определение жизнеспособности местных сообществ.

Первый подход наиболее распространенный. Он, как правило, позволяет проводить сравнительную оценку и ранжирование муниципальных образований по уровню развития основных секторов экономики, в т. ч. и по состоянию социальной сферы $[1,2]$. Так, в соответствии с Комплексной оценкой городских округов и муниципальных районов Краснодарского края по основным среднедушевым показателям социально-экономического состояния и перспективного развития в 2014-2019 гг. Министерства экономики края приводятся данные, на основе которых определяется степень дифференциации в уровне развития муниципальных образований [2]. Из тридцати семи муниципальных районов только один занимает позицию «выше среднего», десять районов относятся к группе «муниципальные образования со средним уровнем развития», двадцать один - к группе «муниципальные образования с уровнем развития ниже среднего» и пять - «с низким уровнем развития». Таким образом, 70\% сельских районов в крае имеют уровень развития ниже среднего и низкий.

Этот инструментарий полезен с точки зрения анализа и оценки сложившихся тенденций в развитии каждого муниципалитета на фоне других и региона в целом.

Проблемный подход ориентирует на оценку существующих позиций муниципального образования по отношению к желаемым целям, определяет степень несоответствия между желаемым и действительным положением дел. Он в наибольшей степени соответствует идеологии стратегического управления развитием, нацеливает на поиск способов преодоления негативных тенденций, на «сгибание тренда».

Это наиболее конструктивный подход с точки зрения управления изменениями. Он предполагает взаимодействие и участие многих представителей интересов - бизнеса власти и населения.

Межсекторное сотрудничество - ключевое условие успеха в стратегическом планировании

Во-первых, стратегическое планирование предполагает изначально партнерство представителей власти, общественности и бизнеса,

Во-вторых, эффективная организация межсекторного сотрудничества в процессе стратегического планирования - залог высокого качества его содержания, достигаемого в ходе диалога многих участников

Сектор - это часть определенной системы, отличающаяся по специфическим характеристикам от других ее составляющих [3].

Эффективное внутри- и межсекторное взаимодействие можно организовать только в 
том случае, если есть четкое представление о секторной структуре, как минимум, следующих систем:

- системы властных отношений, по критерию «степень воздействия на социальноэкономическое развитие»;

- структуры экономики, по критерию «формы собственности»;

- структуры экономики, по критерию отраслевой группировки;

- социальной системы, по критерию разделения населения на группы интересов;

- территориальной системы, по критерию организации пространства жизнедеятельности на определенной территории.

Более подробное представление о системной классификации секторов представлено в табл. 1.

Эффективное внутри- и межсекторное взаимодействие может быть организовано с учетом особенностей каждой из его систем.

В системе властных отношений степень влияния на социально-экономическое развитие соответствует вертикали власти. Если речь идет о местном развитии, есть ряд стратегических вопросов, которые органы местного самоуправления могут решать исключительно во взаимодействии с региональными и федеральными структурами.

Это вызывает необходимость классификации проблем:

- проблемы, поддающиеся решению с использованием местного потенциала;

- проблемы, которые могут быть решены при поддержке и взаимодействии с региональными либо федеральными структурами;

- проблемы, которые невозможно решить без изменения региональных и федеральных институтов.

В условиях ограниченности местных бюджетов сельских муниципальных образований органы местного самоуправления, как правило, ориентируются только на внешнюю поддержку со стороны вышестоящих органов власти.

Особенностью сельской экономики в отличие от городской по критерию «формы собственности» среди субъектов экономической деятельности (представителей, общественного, частного, третьего и четвертого секторов) можно выделить высокую долю четвертого сектора, представленного домохозяйствами, занимающимися нетоварным производством для удовлетворения потребностей членов семьи. Как правило, в ходе оценки экономических ситуаций в сельских районах этот сектор вообще не учитывается. Между тем сектор домохозяйств занимает очень высокую долю в производстве целого ряда сельскохозяйственных продуктов (овощей, фруктов). Это зачастую неформальный сектор экономики, который требует специального внимания и должен стать объектом местной политики, направленной на выращивание будущего предпринимательского сектора.

Представляет интерес приводимая в ряде исследований стран ОЭСР другая классификация типов домохозяйств и предприятий в сельской экономике применительно к условиям переходной экономики. В ней представлены пять типов домохозяйств, охватывающих как крупных товаропроизводителей, так и натуральные хозяйства [4]. Она получила название пяти сельских миров и используется для межсекторального анализа (табл. 2).

Приведенная классификация вызывает определенный интерес применительно к российским условиям, учитывая крайнюю разнородность сельских территорий не только в региональном масштабе, но даже в районном и поселенческом $[4,19]$. В ряде населенных мест возникает ситуация, когда преобладающими становятся четвертый и пятый типы домохозяйств. В качестве примера можно привести результаты исследования, проведенного в Крымском районе Краснодарского края. При низкой доле трудоспособного населения в трудоспособном возрасте (всего 51\% от всего населения района) распределение занятого населения по формам собственности выглядит следующим образом (рис.).

Секторальный анализ по формам собственности, проведенный на основе данных баланса трудовых ресурсов района, показал, что на предприятиях государственной и муниципальной собственности работает около $22 \%$ занятого населения, смешанной (российской) собственности $-14,8 \%$. Основная часть занятого населения сосредоточена на предприятиях и в организациях частной формы собственности (около 62\%). При этом из 62\% занятых 


\section{Системная классификация секторов властных, экономических, социальных и территориальных отношений}

\begin{tabular}{|c|c|c|}
\hline Критерий & & Классификация секторов \\
\hline $\begin{array}{l}\text { Система властных } \\
\text { отношений (по сте- } \\
\text { пени воздействия на } \\
\text { социально- } \\
\text { экономическое раз- } \\
\text { витие }\end{array}$ & $\begin{array}{l}\text { Система власти вклю } \\
\text { федеральный; } \\
\text { региональный; } \\
\text { местный. } \\
\text { На каждом уровне ре } \\
\text { власти. }\end{array}$ & $\begin{array}{l}\text { чает три уровня: } \\
\text { шаются вопросы, отнесенные к компетенции соответствующих органов }\end{array}$ \\
\hline \multirow{4}{*}{$\begin{array}{l}\text { Экономическая си- } \\
\text { стема по формам } \\
\text { собственности }\end{array}$} & $\begin{array}{l}\text { Общественный сек- } \\
\text { тор }\end{array}$ & $\begin{array}{l}\text { Часть экономического пространства, в которой преобладает нерыночный } \\
\text { способ координации экономической деятельности и распределение на } \\
\text { частные и общественные блага, чистые и локальные. Общественный сек- } \\
\text { тор включает государственный и муниципальные секторы. }\end{array}$ \\
\hline & Частный сектор & $\begin{array}{l}\text { Часть экономики, не находящаяся под контролем государства. В нее вхо- } \\
\text { дят домохозяйства и фирмы, принадлежащие частному капиталу. Сектор } \\
\text { обеспечивает частные блага. }\end{array}$ \\
\hline & Третий сектор & $\begin{array}{l}\text { Совокупность организаций, не относящихся ни к частному, ни к обще- } \\
\text { ственному сектору, т. е. некоммерческие негосударственные учреждения. } \\
\text { Основные сферы деятельности - защита населения, благотворительные и } \\
\text { специфические консалтинговые услуги. }\end{array}$ \\
\hline & Четвертый сектор & $\begin{array}{l}\text { Домохозяйства, занимающиеся нетоварным производством для удовлетво- } \\
\text { рения потребностей членов семьи }\end{array}$ \\
\hline \multirow{3}{*}{$\begin{array}{l}\text { Экономическая си- } \\
\text { стема }\end{array}$} & Первичный сектор & $\begin{array}{l}\text { Включает следующие группы отраслей: } \\
\text { - добыча сырья / горнодобывающая промышленность; } \\
\text { - сельское хозяйство; } \\
\text { - рыболовный промысел; } \\
\text { лесничество и рыболовство }\end{array}$ \\
\hline & Вторичный сектор & $\begin{array}{l}\text { Включает все отрасли промышленности, обеспечивающие переработку } \\
\text { сырья и выпуск готовой продукции, в т. ч. строительство }\end{array}$ \\
\hline & Третичный сектор & $\begin{array}{l}\text { Обеспечивает доведение товаров и услуг до конечного потребителя. Услу- } \\
\text { ги носят разнообразный характер - торговля, транспортные, медицинские, } \\
\text { образовательные, юридические, консультационные и туристские и т. п. }\end{array}$ \\
\hline \multirow{4}{*}{$\begin{array}{l}\text { Социальная система } \\
\text { (разделение населе- } \\
\text { ния по группам инте- } \\
\text { ресов) }\end{array}$} & Чиновники & $\begin{array}{l}\text { Основные интересы/ценности: } \\
\text { сохранение должности и авторитета; } \\
\text { карьерный рост; } \\
\text { повышение социального статуса. }\end{array}$ \\
\hline & Предприниматели & $\begin{array}{l}\text { Основные интересы/ценности: } \\
\text { получение большей прибыли; } \\
\text { приобретение статусной собственности; } \\
\text { повышение конкурентоспособности своих предприятий. }\end{array}$ \\
\hline & Наемные работники & $\begin{array}{l}\text { Основные интересы/ценности: } \\
\text { возможности трудоустройства; } \\
\text { достойная заработная плата; } \\
\text { хорошие условия труда; } \\
\text { возможности повышения квалификации и переквалификации; } \\
\text { близость работы к месту жительства. }\end{array}$ \\
\hline & Семьи & $\begin{array}{l}\text { Основные интересы/ценности: } \\
\text { повышение качества жизни; } \\
\text { безопасная и комфортная среда обитания; } \\
\text { доступность необходимых товаров и услуг; } \\
\text { возможности интеллектуального и физического развития детей. }\end{array}$ \\
\hline \multirow{3}{*}{$\begin{array}{l}\text { Территориальная } \\
\text { система - простран- } \\
\text { ство жизнедеятель- } \\
\text { ности на определен- } \\
\text { ной территории }\end{array}$} & $\begin{array}{l}\text { Социальное про- } \\
\text { странство }\end{array}$ & $\begin{array}{l}\text { Включает следующие характеристики: } \\
\text { планировка территории; городской/сельский ландшафт; } \\
\text { архитектурный стиль; } \\
\text { транспортная система; } \\
\text { жкх. }\end{array}$ \\
\hline & $\begin{array}{l}\text { Экономическое } \\
\text { пространство }\end{array}$ & $\begin{array}{l}\text { Является результатом разделения территории на зоны (зонирование): } \\
\text { деловой/административный центр; } \\
\text { промышленные зоны; } \\
\text { торговые зоны; } \\
\text { жилые районы; } \\
\text { зоны отдыха. }\end{array}$ \\
\hline & $\begin{array}{l}\text { Культурное про- } \\
\text { странство }\end{array}$ & $\begin{array}{l}\text { Определяется размещением объектов культурного досуга: } \\
\text { театры; музеи; библиотеки, спортивные объекты. }\end{array}$ \\
\hline
\end{tabular}


АВДЕЕВА Т.T.

ОСОБЕННОСТИ ФОРМИРОВАНИЯ МЕЖСЕКТОРНЫХ ВЗАИМОСВЯЗЕЙ В СЕЛЬСКОЙ ЭКОНОМИКЕ

доля занятых индивидуальным трудом достаточно высокая и составляет 34,4\%. Если учесть, что незанятое население составляет в ряде сельских муниципалитетов от 30 до $50 \%$ от трудоспособного населения, то становится очевидным, насколько масштабной выглядит проблема социальной дифференциации населения на селе.

Таблииа 2

Типы домохозяйств и предприятий в модели «Пять сельских миров»

\begin{tabular}{|c|c|}
\hline Типы домохозяйств & Основные характеристики \\
\hline $\begin{array}{l}\text { Сельский мир } 1 \\
\text { Домохозяйства, занимающиеся } \\
\text { крупным товарным производством } \\
\text { сельскохозяйственной продукции и } \\
\text { владеющие коммерческими пред- } \\
\text { приятиями }\end{array}$ & $\begin{array}{l}\text { незначительное число в развивающихся странах; } \\
\text { занимаются высокоприбыльным экспортоориентированным сельхозпро- } \\
\text { изводством; } \\
\text { легкий доступ к финансовым институтам, инструментам управления рис- } \\
\text { ками, информации и инфраструктурам; } \\
\text { имеют значительный вес в национальной политике и институтах, оказы- } \\
\text { вающих влияние на их предприятия. }\end{array}$ \\
\hline $\begin{array}{l}\text { Сельский мир } 2 \\
\text { Традиционные землевладельцы и } \\
\text { предприятия, неконкурентоспособ- } \\
\text { ные на международных рынках }\end{array}$ & $\begin{array}{l}\text { значительное число сельских домохозяйств и фермеров; } \\
\text { зачастую часть местной элиты, но с малым влиянием на национально } \\
\text { уровне; } \\
\text { достаточно крупные хозяйства, занимающиеся одновременно коммерче- } \\
\text { ским производством и обеспечением своих потребностей; } \\
\text { имели возможность получить основные услуги (такие? как финансовые) } \\
\text { для изменения структуры хозяйства, но не более того; } \\
\text { доступность инструментов управления рисками ограничена. }\end{array}$ \\
\hline $\begin{array}{l}\text { Сельский мир } 3 \\
\text { Домохозяйства, занимающиеся в } \\
\text { основном для собственных потреб- } \\
\text { ностей, и микропредприятия }\end{array}$ & $\begin{array}{l}\text { большое количество рыболовов, скотоводов, мелких землевладельцев и } \\
\text { связанных с ними микропредприятий; } \\
\text { обеспечение пропитания семьи - их главная забота; } \\
\text { очень ограниченный доступ к услугам (например, кредит); } \\
\text { чаще всего хозяйства в депрессивных районах и районах с плохой экоси- } \\
\text { стемой. }\end{array}$ \\
\hline $\begin{array}{l}\text { Сельский мир } 4 \\
\text { Мало- и безземельные домохозяй- } \\
\text { ства и микропредприятия }\end{array}$ & $\begin{array}{l}\text { чаще управляются женщинами; } \\
\text { главный источник дохода - обмен урожаем с другими домохозяйствами и } \\
\text { работа в качестве наемных работников; } \\
\text { часто уезжают на работу в экономические центры ежедневно, на сезон } \\
\text { или навсегда, однако низкий уровень образования является главным пре- } \\
\text { пятствием для переезда. }\end{array}$ \\
\hline $\begin{array}{l}\text { Сельский мир } 5 \\
\text { Постоянно нуждающиеся или нера- } \\
\text { ботающие домохозяйства }\end{array}$ & $\begin{array}{l}\text { зачастую продавшие или потерявшие свое хозяйство в период кризиса; } \\
\text { крайне необходима поддержка от родственников. местных организаций, } \\
\text { национального правительства; } \\
\text { чаще всего социально исключены из жизни местного сообщества. }\end{array}$ \\
\hline
\end{tabular}

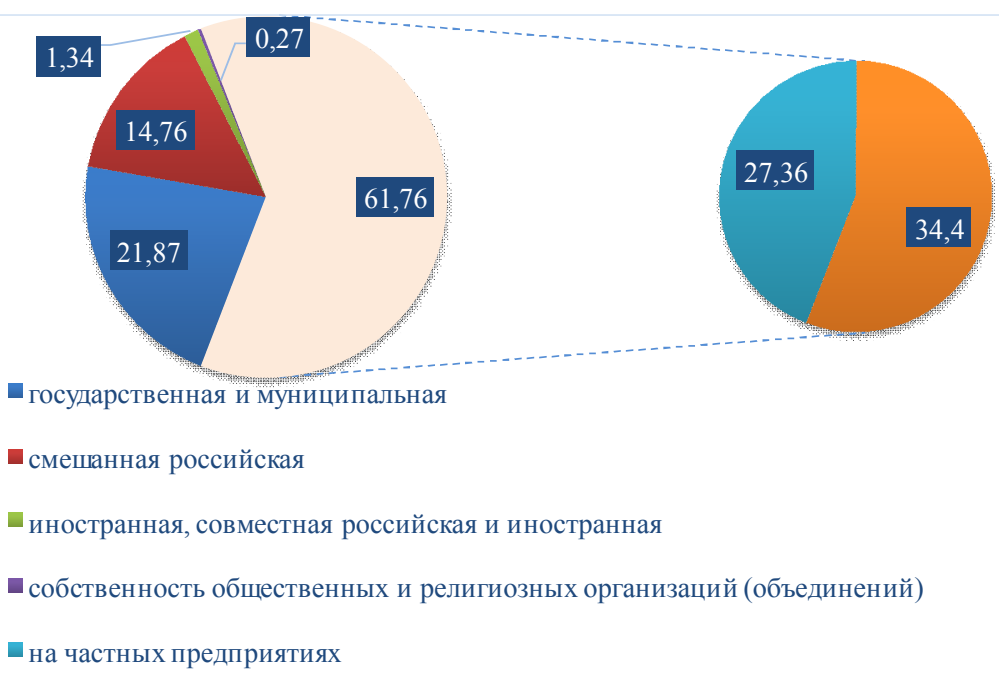

Pис. Распределение занятых в экономике сельского района по формам собственности 
Основными проблемами в сфере труда и занятости являются:

- низкая доля занятого населения и высокая доля неработающих домохозяйств (3-5 категории из приведенной выше классификации);

- снижение занятости в малом бизнесе при росте числа малых предприятий;

- высокая доля занятого населения в первичном секторе экономики [5,9].

Таким образом, обострение социальной ситуации проявляется в росте оттока населения из села. В результате сокращается количество населенных пунктов в сельских районах, обостряется проблема обезлюдения. Оценка демографической ситуации, проведенная в рамках грантового исследования, позволила представить всю сложность ситуации. Так, в одном из густонаселенных районов Краснодарского края - Крымском районе из 89 населенных пунктов под угрозой исчезновения находятся около 10 сельских малонаселенных пунктов (с численностью населения до 15-20 чел.), в которых проживают преимущественно жители пенсионного возраста.

Секторальный анализ по отраслевой структура экономики сельских территорий традиционно применяется в оценках с точки зрения поиска возможностей интеграции первичного и перерабатывающего секторов [5]. Однако для сельских территорий исторически преимущественно развивается первичный сектор. По мере роста душевого дохода и, соответственно, изменения потребительского спроса развиваются вторичный и, наконец, третичный секторы. При этом сектор услуг в экономике сельских территорий, как правило, развит очень слабо. Преобладают лишь услуги, имеющие бюджетную поддержку - образование и первичная медицинская помощь. Определенный импульс получила торговля. Туристские услуги, спрос на которые растет со стороны горожан, пока наименее развиты.

Пространственные аспекты секторального анализа также подтвердили тенденцию трудовой миграции населения в центры экономической активности. Как правило, ими являются центры административных районов или территории, оказывающиеся под влиянием города.

Проведенный сравнительный анализ концептуальных подходов к проблемам сельского развития позволил выделить три основные концепции:

- концепция, отождествляющая сельское развитие с модернизацией сельского хозяйства и агропродовольственного комплекса (модель отраслевого развития);

- концепция, связывающая сельское развитие с преодолением отсталости сельских территорий (перераспределительная модель);

- концепция, которая соотносит сельское развитие с развитием сельских территорий в целом путем использования всех ресурсов (человеческих, физических, природных, ландшафтных и пр.) и интеграции между всеми компонентами и отраслями на местном уровне (интеграционная модель) [6].

Первая и вторая концепция не учитывают межсекторные отношения, ориентируют политику на развитие отдельного сектора экономики.

Третья в большей мере ориентирована на развитие межсекторных взаимосвязей, что предполагает сотрудничество власти (государственной и муниципальной), бизнеса и населения.

Межсекторное сотрудничество может дать положительные результаты тогда, когда:

- попытки решения проблем в рамках одного сектора оказываются неудачными (например, производство сельхозпродукции нуждается в переработке, или на основе сельского хозяйства можно развивать услуги агротуризма);

- решение проблем требует информации и ресурсов, доступных более чем одному сектору (например, формирование кластерных образований на основе создания крупных логистических центров, когда поставщиками продукции может стать малый семейный бизнес);

- ранее сложившиеся отношения между ключевыми игроками не препятствует сотрудничеству (отношения между администрацией района и бизнес-структурами) [8].

Ключевым механизмом формирования межсекторного сотрудничества является стратегическое планирование, предполагающее партнерство представителей власти, бизнеса и населения. 
Лuтература

1. Якимеи, В. Н. Межсекторное социальное партнерство : основы, теория, приниипы, механизмы / В. Н. Якимец. - М. : Едиториал УРСС, 2004.

2. Комплексная оченка городских округов и муниципальных районов Краснодарского края по основным среднедушевым показателям сочииально-экономического состояния и перспективного развития в 2015-2020 г2. [Электронный pecypc]. - URL : http://economy.krasnodar.ru/macroeconomics/ comprehensive-assessment-of-the-socio-economic-development-of-city-districts-and-municipal-areas-of-/ (дата обращения 23.12.2018).

3. Якимеи, В. Н. Межсекторное социальное партнерство в России : механизмы, оченка состояния и проблемь развития на региональном уровне / В. Н. Якимеи // Социальное партнерство и развитие институтов гражданского общества в регионах и мунищипалитетах. Практика межсекторного взаимодействия : практ. пособие ; под ред. А. Е. Шадрина. - М. : Агентство соииальной информаuиu, 2010. C. 222-249.

4. Revamping the OECD's Five Rural Worlds Model for Poverty-Oriented/Inter-Sectoral Analysis, Communication and Planning / German Development Institute // Briefing Paper. 2016. No.16.

5. Sector Approaches in Agriculture and Rural Development / Reference Document No. 5 // EUROPEAN COMMISSION. - Luxemburg : Office for Official Publications of the European Communities. 2009.

6. Авдеева, Т. Т., Скрипиль, И. А. Взаимодействие городских и сельских территорий в экономическом пространстве региона : монография. - Краснодар : Изд.-полиграф. иентр КубГУ, 2018.

7. Лаврова, Т. Г. Лучшие практики межсекторного партнерства в сельских местных сообществах Краснодарского края // Инновачионная экономика : перспективы развития и совершенствования. 2018. № 8 (34).

8. Kalegaonkar, A, Brown, D. Intersectoral Cooperation : Lessons For Practice / Institute for Development Research. - Boston, 2000.

9. Лаврова, Т. Г. Развитие системы поддержки малого бизнеса в сельских муниципальных образованиях // Наука и образование : новое время. 2018. № 4 (11). C.11-15.

10. Лаврова, Т. Г., Саакян, А. Ф. Развитие форм организащии сбыта продовольственной продукиии малых предприятий // Актуальные проблемы стратегического управления территориальныл развитием : сб. матер. Всероссийской науч.-практ. конф. - Краснодар : Кубанский гос. ун-т, 2018.

11. Родин, А. В. Территориальное общественное самоуправление в системе межсекторного взаимодействия // Наука и образование: новое время. 2018. № 4 (11). C.15-17.

12. Родин, А. В. Межсекторное взаимодействие как организационно- управленческий ресурс развития туристического комплекса Краснодарского края // Актуальные проблемы стратегического управления территориальным развитием : сб. матер. Всероссийской науч.-практ. конф. - Краснодар : Кубанский гос. ун-т, 2018. С. 252-259.

13. Родин, А. В., Будко, А. С. Формирование иифровой культуры как ресурса развития межсекторного взаимодействия // Актуальные проблемы стратегического управления территориальным развитием : сб. матер. Всероссийской науч.-практ. конф. - Краснодар : Кубанский государственный университет, 2018. C. 49-55.

14. Родин, А. В. Цифровая трансформация межсекторного взаимодействия в реализации концепџии «Smart Kuban» // Цифровой регион : опьы, компетениии, проекты : материаль Международной научно-практической конферениии (30 ноября 2018 г., г. Брянск). - Брянск : Брянский государственный инженерно-технологический университет, 2018.

15. Родин, А. В. Институцииональные условия межсекторного взаимодействия в обеспечении устойчивого развития территорий // Modern Economy Success : международный научный журнал. 2018. № 4.

16. Родин, А. В. Реализащия кониепщии «Умный регион» в Стратегии развития Краснодарского края 2030 // DSEME 2018 : материаль I Международной конференции по вопросам ичифровизаиии общества, экономики, управления и образования (14-15 декабря 2018 г., г. Екатеринбург). - Екатеринбург : УрФУ, 2018.

17. Урманов, Д. В. Основные приоритеты межсекторного взаимодействия в развитии экономики Крымского района Краснодарского края // Наука и образование : новое время (сетевое издание). 2018. № 6. - URL : https://articulus-info.ru/category/08-00-00-ekonomicheskie-nauki/?tag=6-noyabrdekabr-2018-g (дата обрамения 10.12.2018). C.174-181.

18. Урманов, Д. В., Билле, Р. Е., Еременко, М. В. Основные направления межсекторного развития предгорной экономической зоны Краснодарского края // Актуальные проблемы стратегического управления территориальным развитием : сб. матер. Всероссийской науч.-практ. конф. - Краснодар : Кубанский гос. ун-т, 2018. С. 322-326.

19. Фадеева, О. П. Сельские сообщества и хозяйственные уклады : от выюживания к развитию ; под ред. З.И. Калугиной. - Новосибирск : ИЭОПП СО РАН, 2015.

20. Шамян, Е. А., Авдеева, Т. Т. Межсекторное взаимодействие : пути интеграции университетарегиона-бизнеса // Актуальные проблемы стратегического управления территориальным развитием : сб. матер. Всероссийской научно-практической конференции (Краснодар 21 мая 2018). - Краснодар : Кубанский гос.ун-т, 2018. С. 358-367.

\section{References:}

1. Yakimets, V. N. Intersector social partnership : fundamentals, theory, principles, mechanisms / V.N. Yakimets. - M. : Editorial URSS, 2004. 
2. Comprehensive assessment of urban districts and municipal districts of the Krasnodar Territory on the main average per capita indicators of socio-economic status and future development in 2015-2020 [Electronic resource]. -URL : http://economy.krasnodar.ru/macroeconomics/comprehensive-assessmentof-the-socio-economic-development-of-city-districts-and-municipal-areas-of - / (appeal date 12/23/2018).

3. Yakimets, $V . N$. Intersectoral social partnership in Russia : mechanisms, assessment of the state and problems of development at the regional level / V.N. Yakimets // Social partnership and development of civil society institutions in regions and municipalities. The practice of intersectoral interaction : a practical guide; ed. A. E. Shadrina. - M. : Agency of Social Information, 2010. P. 222-249.

4. Revamping the OECD's Five Rural Worlds Model for Poverty-Oriented / Inter-Sectoral Analysis, Communication and Planning / German Development Institute // Briefing Paper. 2016. No.16.

5. Sector Approaches in Agriculture and Rural Development / Reference Document No. 5 / EUROPEAN COMMISSION. - Luxemburg : Office for Official Publications of the European Communities, 2009.

6. Avdeeva, T. T., Skripil, I. A. The interaction of urban and rural areas in the economic space of the region : a monograph. - Krasnodar : KubSU Publishing and Printing Center, 2018.

7. Lavrova, T. G. Best Practices of Intersectoral Partnership in Rural Local Communities of the Krasnodar Territory // Innovative Economy : Prospects for Development and Improvement. 2018. № 8 (34).

8. Kalegaonkar, A, Brown, D. Intersectoral Cooperation : Lessons For Practice / Institute for Development Research. - Boston, 2000.

9. Lavrova, T. G. Development of a small business support system in rural municipalities // Science and education : a new time. 2018. No. 4 (11). P.11-15.

10. Lavrova, T. G., Sahakyan, A. F. The development of forms of organization of sales of food products of small enterprises // Actual problems of strategic management of territorial development : Sat. mater AllRussian scientific-practical. conf. - Krasnodar : Kuban State University, 2018.

11. Rodin, A. V. Territorial public self-government in the system of intersectional interaction // Science and education: a new time. 2018. No. 4 (11). P. 15-17.

12. Rodin, A. V. Intersectoral interaction as an organizational and managerial resource for the development of the tourist complex of the Krasnodar Territory // Actual problems of strategic management of territorial development : Sat. mater All-Russian scientific-practical. conf. - Krasnodar : Kuban State University Press, 2018. P. 252-259.

13. Rodin, A. V., Budko, A. S. Formation of digital culture as a resource for the development of intersectoral interaction // Actual problems of strategic management of territorial development : Sat. mater AllRussian scientific-practical. conf. - Krasnodar : Kuban State University, 2018. P. 49-55.

14. Rodin, A. V. Digital Transformation of Intersectoral Interaction in Implementing the Smart Kuban Concept // Digital Region : Experience, Competences, Projects : Materials of the International Scientific and Practical Conference (November 30, 2018, Bryansk). - Bryansk : Bryansk State University of Engineering and Technology, 2018.

15. Rodin, A. V. Institutional conditions for intersectoral collaboration in ensuring sustainable development of territories // Modern Economy Success. 2018. No. 4.

16. Rodin, A. V. Implementing the "Smart Region" concept in the Development Strategy of Krasnodar Region 2030 // DSEME 2018 : Proceedings of the I International Conference on the Digitalization of Society, Economics, Management and Education (December 14-15, 2018, Yekaterinburg). - Ekaterinburg : UrFU, 2018.

17. Urmanov, D. V. The main priorities of intersectoral interaction in the development of the economy of the Crimean region of the Krasnodar Territory // Science and education : a new time (network edition). 2018. No. 6. - URL : https://articulus-info.ru/category/08-00-00-ekonomicheskie-nauki/?tag=6-noyabrdekabr-2018-g (access date 10.12.2018). C.174-181.

18. Urmanov, D. V., Bille, R. E., Eremenko, M. V. The main directions of intersectoral development of the foothill economic zone of the Krasnodar Territory // Actual problems of strategic management of territorial development : Sat. mater All-Russian scientific-practical. conf. - Krasnodar : Kuban State University Press, 2018. P. 322-326.

19. Fadeeva, O. P. Rural communities and economic structures : from survival to development ; ed. Z.I. Kalugina. - Novosibirsk: IEEPP SB RAS, 2015.

20. Shamyan, E. A., Avdeeva, T. T. Intersectional interaction : ways of integrating a university-regionbusiness // Actual problems of strategic management of territorial development: collection of articles. mater All-Russian Scientific and Practical Conference (Krasnodar, May 21, 2018). - Krasnodar : Kuban State University, 2018. P. 358-367. 